\title{
The Dual Amylin and Calcitonin Receptor Agonist KBP-088 Induces Weight Loss and Improves Insulin Sensitivity Superior to Chronic Amylin Therapy ${ }^{[}$
}

\author{
Anna Thorsø Larsen, Nina Sonne, Kim Vietz Andreassen, Kristoffer Gehring, \\ Morten Asser Karsdal, and Kim Henriksen
}

Nordic Bioscience Biomarkers and Research, Department of Endocrinology, Herlev, Denmark

Received February 20, 2019; accepted April 17, 2019

\begin{abstract}
KBP-088 (KeyBiosciencePeptide 088) is a potent dual amylin and calcitonin receptor agonist (DACRA). DACRAs are known to elicit potent activity in terms of typical amylin-induced responses, such as reducing food intake and body weight. However, to what extent amylin infusion can mimic the effects of the dual agonist KBP-088 is unknown. We studied the effect of acute dosing with KBP-088 $(5 \mu \mathrm{g} / \mathrm{kg})$ and rat amylin $(100,300$, and $1000 \mu \mathrm{g} / \mathrm{kg}$ ) and subsequently compared the chronic effect of KBP-088 (5 $\mu \mathrm{g} / \mathrm{kg}$ per day) to increasing doses of rat amylin $(100,300$, and $1000 \mu \mathrm{g} / \mathrm{kg}$ per day) delivered by continuous subcutaneous infusion, in high-fat diet (HFD) fed Long-Evans rats. Furthermore, acute amylin sensitivity was investigated. Single dose KBP-088 $(5 \mu \mathrm{g} / \mathrm{kg})$ potently reduced acute food intake for a prolonged period compared with amylin $(100,300$,
\end{abstract}

and $1000 \mu \mathrm{g} / \mathrm{kg}$ ), confirming the difference in potency. Independent of dose, chronic amylin administration $(100,300$, and $1000 \mu \mathrm{g} / \mathrm{kg}$ per day) was less effective than KBP-088 $(5 \mu \mathrm{g} / \mathrm{kg}$ per day) in inducing body weight loss (15\% with KBP-088, and $5 \%, 9 \%$, and $8 \%$ with amylin, vehicle corrected) and reducing overall adiposity in HFD rats. Moreover, KBP-088 improved oral glucose tolerance with significantly reduced insulin levels ( $80 \%$ reduction) that were better than all doses of amylin ( $68 \%, 53 \%$, and $7 \%$ reduction). Acute amylin sensitivity was independent of the chronic treatment. Dual activation of amylin and calcitonin receptors by KBP-088 is superior to amylin in reducing body weight and improving glucose tolerance, indicating a role for the calcitonin receptor.

\section{Introduction}

Amylin is a neuroendocrine peptide hormone with anorectic and glucoregulatory actions. In the postprandial state amylin complements insulin in lowering blood glucose by suppressing inappropriate glucagon secretion and slowing gastric emptying (Hay et al., 2015; Hay, 2017). Chronic amylin administration has been shown to reduce body weight and food intake in diet-induced obese rodents (Mack et al., 2003; Roth et al., 2006). In obese subjects, the stable amylin analog pramlintide showed potential for reduction of body weight and food intake (Aronne et al., 2007; Smith et al., 2008). Additionally, pramlintide has been approved as adjunct to insulin therapy for treatment of type 1 and 2 diabetes due to its ability to regulate postprandial hyperglycemia and reduce body weight and glycated hemoglobin A1c (Weyer et al., 2001; Hollander et al., 2003; Ratner et al., 2004; Riddle et al., 2007; Ryan et al., 2009). A common limitation of amylin analogs is their limited potency in vivo.

This work was supported by a grant from the Danish Research Foundation (Den Danske Forskningsfond).

M.A.K. and K.H. own stock in Nordic Bioscience. M.A.K., K.V.A., and K.H hold patents in KBP-088. All other authors disclose no conflict of interest.

https://doi.org/10.1124/jpet.119.257576.

S This article has supplemental material available at jpet.aspetjournals.org.
The calcitonin receptor (CTR) is a G protein-coupled receptor that is able to interact with receptor-activity-modifying proteins (RAMPs). Amylin receptors (AMY-Rs) are formed by the interaction of a RAMP with a CTR, which alters the properties of the CTR from a calcitonin receptor to a highaffinity receptor for amylin (Christopoulos et al., 1999; Muff et al., 1999). Thus, the CTR and AMY-R share the same core structure since AMY-Rs are CTRs with a RAMP. Dual amylin and calcitonin receptor agonists (DACRAs) differ from amylin since they activate both the AMY-R and the CTR for an extended period (Gydesen et al., 2016). KBP-088 (KeyBiosciencePeptide 088, the DACRA tested in the present study) and other DACRAs have been shown to active both the AMY-R and CTR without off-target activation of the calcitonin gene-related peptide receptor, which is the closest related receptor (Andreassen et al., 2014a; Gydesen et al., 2016, 2017). Furthermore, DACRAs elicit superior activity in terms of typical amylin-induced responses including reduction of food intake, body weight, and glucagon secretion (Roth et al., 2006; Trevaskis et al., 2010; Andreassen et al., 2014a; Gydesen et al., 2016; Hjuler et al., 2016). However, it is unknown how the dual receptor activation by DACRAs compares to activation of the AMY-R by the natural ligand amylin when comparing the peptides directly by correcting for the different activity profiles.

ABBREVIATIONS: AMY-R, Amylin Receptor; AST, amylin sensitivity test; CTR, calcitonin receptor; DACRA, dual amylin and calcitonin receptor agonist; HFD, high-fat diet; KBP-088, KeyBiosciencePeptide 088; OGTT, oral glucose tolerance test; RAMP, receptor-activity-modifying protein. 
In this study, we compared the effect of a highly potent DACRA, KBP-088, and increasing doses of rat amylin on the long-term efficacy on body weight, food intake, and glucose tolerance in rats fed a high-fat diet (HFD). To compensate for the different activity profiles, peptides were delivered by continuous subcutaneous infusion. In addition, the acute amylin sensitivity was assessed during the chronic study.

\section{Materials and Methods}

\section{Peptide Therapy}

Synthetic KBP-088 (SynPeptide, Shanghai, China) and rat amylin (SynPeptide) were dissolved in saline for subcutaneous delivery. The amino acid sequence of KBP-088 has previously been published by Gydesen et al. (2016) and can be found in Table 1 head to head with the amino acid sequence of rat amylin. The dose chosen for KBP-088 administration was based on previous studies using KBP-088 (Gydesen et al., 2016) and other DACRAs (Hjuler et al., 2015, 2016, 2017; Gydesen et al., 2017).

\section{Animal Experiments}

All animal procedures were performed in accordance with guidelines from the Animal Welfare Division of the Danish Ministry of Justice under the institutional license issued to Nordic Bioscience (2016-15-0201-00910). Animals were health monitored daily and no behavioral signs of compound toxicity were observed. All animals were housed pairwise (in type IV $\mathrm{H}$ cages (Scanbur A/S, Karlslunde, Denmark) with standard wood chips enriched with red-tinted huts, nest material, and sticks) under controlled temperature $\left(21-23^{\circ} \mathrm{C}\right.$, $55 \%-65 \%$ relative humidity) and a normal 12-hour light/dark cycle with ad libitum access to food and water. All animals were fed a HFD diet containing $62 \mathrm{kcal} \%$ fat, $18 \mathrm{kcal} \%$ protein, and $20 \mathrm{kcal} \%$ carbohydrates (TestDiet, London, UK) from arrival and throughout the study period.

Acute Study. Forty male Sprague-Dawley rats (22 weeks of age; 16 weeks on HFD) (Envigo, Venray, The Netherlands) were allocated into treatment groups according to body weight $(n=8 \mathrm{rats} /$ treatment group). Overnight fasted animals received a single dose of KBP-088 $(5 \mu \mathrm{g} / \mathrm{kg}$, s.c.), rat amylin $(100,300$, or $1000 \mu \mathrm{g} / \mathrm{kg}$, s.c. $)$, and vehicle (saline, subcutaneously) and food intake and body weight were monitored 4, 24, and 48 hours postinjection.

Chronic Study. Forty male Long-Evans rats (Envigo, Indianapolis, IN) were obtained at 4 to 5 weeks of age. After 10 weeks on a HFD, rats were allocated into treatment groups according to body weight ( $n=8 \mathrm{rats} /$ treatment group). The rats received doses of KBP-088 (5 $\mu \mathrm{g} / \mathrm{kg}$ per day, s.c.), rat amylin (100, 300, or $1000 \mu \mathrm{g} / \mathrm{kg}$ per day, s.c.), and vehicle (saline, subcutaneously) for 4 weeks. Peptides and vehicle were delivered by continuous infusion using Alzet osmotic pumps (model 2ML4; AgnTho's, Lidingö, Sweden). Animals were anesthetized with isoflurane and surgically equipped with an osmotic pump subcutaneously in the neck region. Initially, the skin was locally anesthetized at the site of incision by Marcaine injection and animals received analgesia (Rimadyl injection) 3 days postoperation. Body weight and food intake were monitored daily throughout the study period. At study end an oral glucose tolerance test (OGTT) was performed in overnight fasted animals. To assess the effect on gastric emptying, rats received acetaminophen $(40 \mathrm{mg} / \mathrm{kg})$ by oral gavage $(4 \mathrm{ml} / \mathrm{kg})$ together with a glucose bolus during the OGTT and plasma acetaminophen was measured 15, 30, and 60 minutes postadministration. At study end animals were euthanized by exsanguination (under isoflurane anesthesia), followed by dissection. Epididymal, perirenal, and subcutaneous inguinal fat depots and liver were surgically removed and weighed. 


\section{Amylin Sensitivity Test}

At 7, 14, and 21 days of treatment an acute amylin sensitivity test (AST) was performed in overnight fasted animals. Independent of chronic treatment, animals received a single injection of rat amylin (300 $\mu \mathrm{g} / \mathrm{kg}$, s.c.) or saline (vehicle group) at time 0 and food intake was monitored the following 2,4 , and 24 hours. Food consumption was used as an estimate of sensitivity to amylin.

\section{Oral Glucose Tolerance Test}

An OGTT was performed after 4 weeks of treatment in animals fasted for 12 hours. A glucose bolus $(2 \mathrm{~g} / \mathrm{kg}$; Sigma-Aldrich, Copenhagen, Denmark) was administered by oral gavage $(4 \mathrm{ml} / \mathrm{kg})$ at time 0 . EDTA plasma samples were collected from the tail vein before glucose challenge ( 0 minutes) and then the following 15,30 , 60 , and 120 minutes post glucose challenge. Blood glucose was monitored at time $0,15,30,60,120$, and 180 minutes post glucose challenge.

\section{Biochemical Analysis}

Blood samples were collected in EDTA tubes and centrifuged at $5000 \mathrm{rpm}$ for 10 minutes at $4^{\circ} \mathrm{C}$ and kept at $-20^{\circ} \mathrm{C}$ until further analysis. Blood glucose was monitored by the Accu-Check Avia monitoring system (Roche Diagnostics, Rotkreuz, Switzerland). Plasma levels of insulin (Mercodia Rat Insulin ELISA; Mercodia AB, Uppsala, Sweden) and acetaminophen (Acetaminophen Direct ELISA Kit; Immuneanalysis, Pomona, CA) were analyzed according to the manufacturer's instructions.

\section{Statistical Analysis}

All data are presented as mean \pm S.E.M. The statistical analysis of group differences was assessed using one-way ANOVA followed by post-hoc test, Tukey's test for multiple comparisons, and Dunnett's test for comparison with vehicle. All analyses were performed using GraphPad Prism 7 software (GraphPad Prism, San Diego, CA). A value of $P<0.05$ was considered statistically significant.

\section{Results}

KBP-088 Potently Reduces Acute Food Intake, while Amylin Only Induces Transient Reduction. A single dose of both amylin $(100,300$, or $1000 \mu \mathrm{g} / \mathrm{kg})$ and KBP-088 $(5 \mu \mathrm{g} / \mathrm{kg}$ ) potently suppressed food intake for 4 hours postinjection, while only KBP-088 had a prolonged response, supressing food intake 24 hours postinjection. In addition, there was no difference between the tested amylin doses $(100,300$, and $1000 \mu \mathrm{g} / \mathrm{kg}$ ) (Fig. 1A). The effect on food intake was reflected in the body weight changes. KBP-088 induced a marked body weight reduction that lasted 48 hours postinjection, while amylin only had a transient effect on body weight (Fig. 1B).

KBP-088 Induces Greater Weight Loss than HighDose Amylin. Four weeks of continuous infusion treatment with KBP-088 (5 $\mu \mathrm{g} / \mathrm{kg}$ per day) and amylin $(100,300$, or $1000 \mu \mathrm{g} / \mathrm{kg}$ per day) resulted in a sustained body weight loss in HFD rats; KBP-088 with the greatest efficacy (Fig. 2, A, C, and E). Chronic treatment with KBP-088 resulted in 15\% vehiclecorrected body weight loss, while amylin at 100, 300, and $1000 \mu \mathrm{g} / \mathrm{kg}$ per day resulted in $5 \%, 9 \%$, and $8 \%$ weight reduction, respectively. In all treatment groups, a large reduction in food intake was observed in the first week of the treatment period, corresponding well to the marked weight loss in the initial phase of the study (Fig. 2, A and B). Both $\mathrm{KBP}-088$ and amylin at $300 \mu \mathrm{g} / \mathrm{kg}$ per day resulted in significantly lower accumulated food intake compared with vehicle (Fig. 2D), while KBP-088 resulted in greater body weight loss compared to all doses of amylin (Fig. 2E). Importantly, a stability test of amylin in the concentrations used in the osmotic pumps showed that the peptide remained stable throughout the study (Supplemental Fig. 1).

KBP-088 Reduces Overall Adiposity in HFD Fed Rats. At study end adipose tissues and liver were isolated and weighed. In conjunction with the significant reduction in body weight, the weights of all three adipose tissues were significantly reduced in the KBP-088-treated group (Fig. 3, A-C). Again, KBP-088 was superior to amylin treatment, corresponding well with the effects observed for body weight and glucose tolerance. Only the weight of epididymal adipose tissue was significantly reduced by amylin (300 and $1000 \mu \mathrm{g} / \mathrm{kg}$ per day) (Fig. 3C). None of the treatments significantly altered liver weights at study end (Fig. 3D).

Independent of Dose, Amylin is Less Effective than KBP-088 at Reducing Blood Glucose Levels during an OGTT. An OGTT was performed after 4 weeks of chronic treatment. KBP-088 (5 $\mu \mathrm{g} / \mathrm{kg}$ per day) significantly improved oral glucose tolerance, with markedly reduced plasma insulin levels (Fig. 4). Amylin treatment resulted in a small and nonsignificant improvement in glucose tolerance, albeit independent of the dose given (Fig. 4, A and C). Interestingly, only low and intermediate doses of amylin (100 and $300 \mu \mathrm{g} / \mathrm{kg}$ per day) reduced insulin levels. This difference in insulin levels resulted in significantly different incremental area under the curve values in the amylin-treated groups (Fig. 4D).
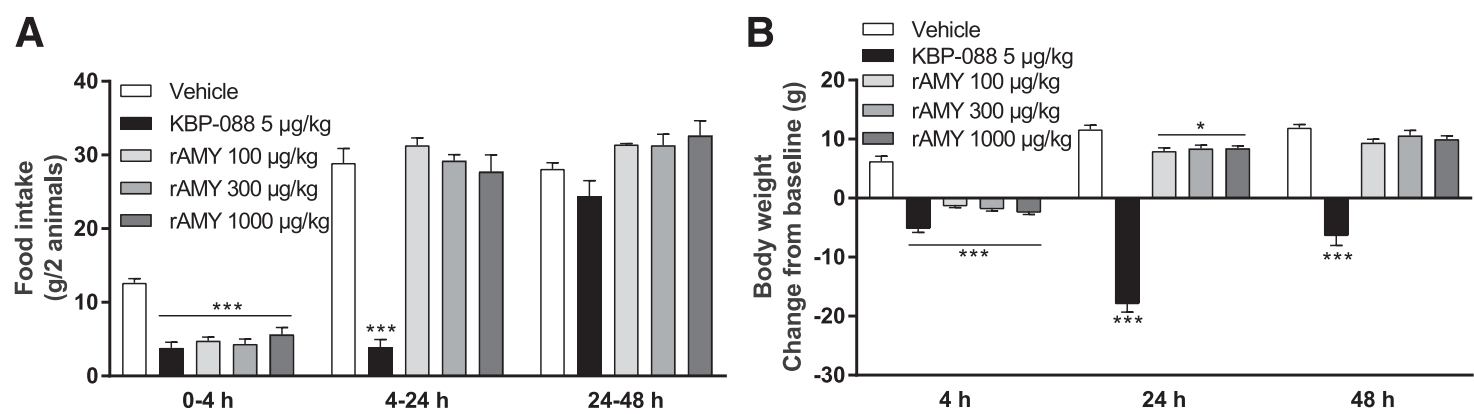

Fig. 1. Effect on food intake (A) and body weight change (B) post a single subcutaneous injection of KBP-088 or rat amylin (rAMY) in HFD fed SpragueDawley rats. $n=8$ rats per group. Statistical analysis between groups was evaluated by one-way ANOVA and Dunnett's test for comparison with vehicle: $* P<0.05$ and $* * * P<0.001$ compared with vehicle. All data are mean \pm S.E.M. 
A

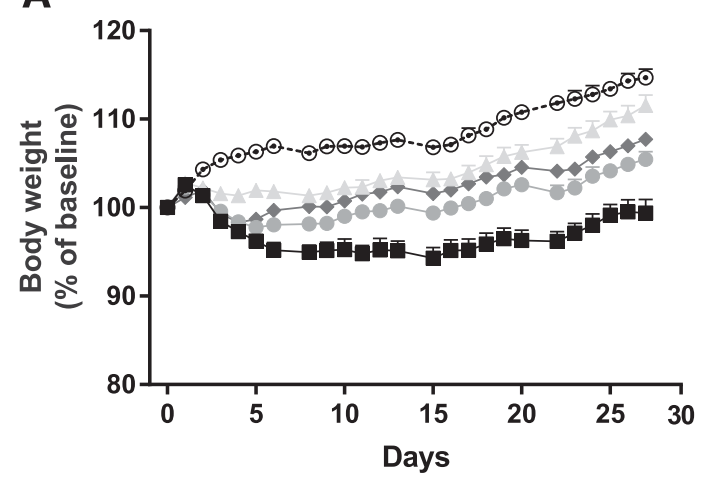

B

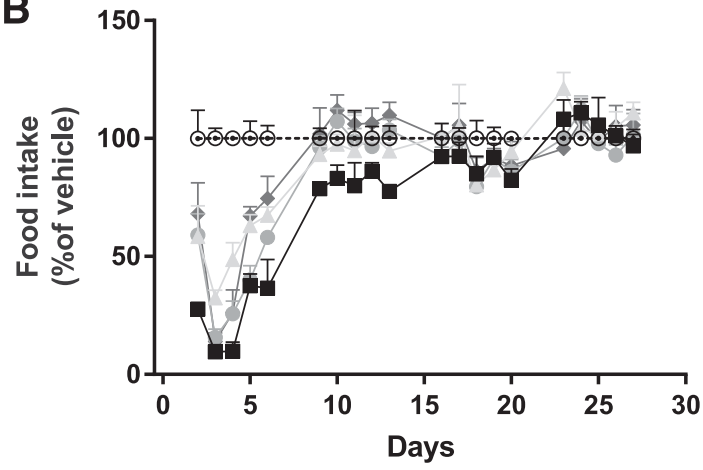

-๑. Vehicle

C

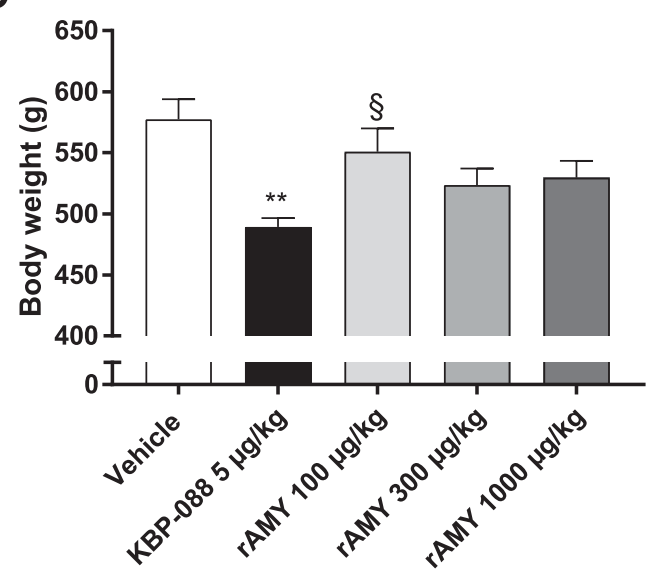

E

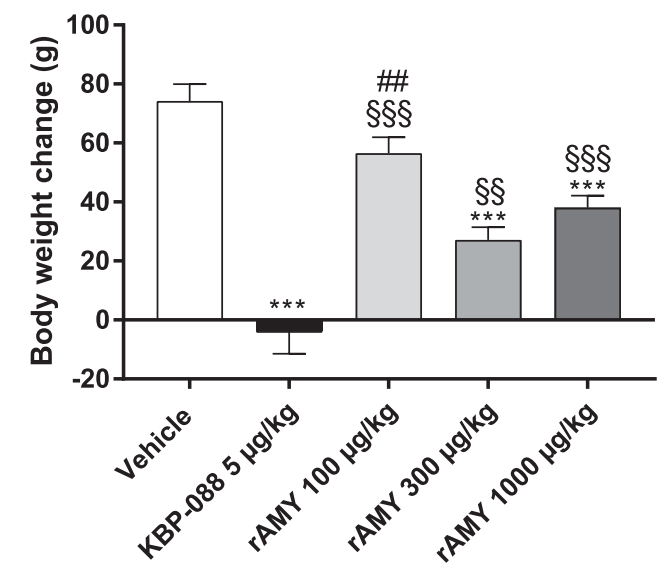

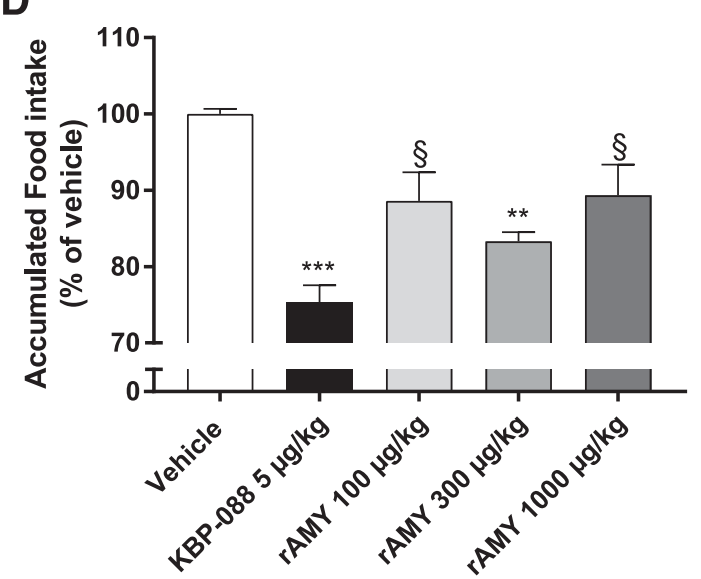

Fig. 2. Baseline-corrected body weight (A) and vehicle-corrected food intake (B) of HFD fed Long-Evans rats during the study. (C) Endpoint body weights. (D) Accumulated food intake for the entire duration of the study. (E) Body weight change at study end. $n=8$ rats per group. Statistical analysis between groups was evaluated by one-way ANOVA and Tukey's multiple comparisons test: ** $P<0.01$ and $* * * P<0.001$ compared with vehicle; ${ }^{\S} P<0.05,{ }^{, \S} P<0.01$, and ${ }^{\S \S \S} P<0.001$ compared with KBP-088; and ${ }^{\# \#} P<0.01$ compared with amylin $300 \mu \mathrm{g} / \mathrm{kg}$ per day. All data are mean \pm S.E.M.; rAMY, rat amylin.

Chronic KBP-088 and Amylin Treatment Reduce Gastric Emptying. The rate of gastric emptying was assessed during OGTT at 15,30 , and 60 minutes post acetaminophen administration. Fifteen minutes post acetaminophen administration both KBP-088 ( $5 \mu \mathrm{g} / \mathrm{kg}$ per day) and amylin (100 and $300 \mu \mathrm{g} / \mathrm{kg}$ per day) resulted in significant vehicle-corrected reduction of the gastric emptying rate (Fig. 5A). The effect was even more pronounced 30 minutes post acetaminophen administration, where all treatment groups significantly reduced the vehicle-corrected 
A
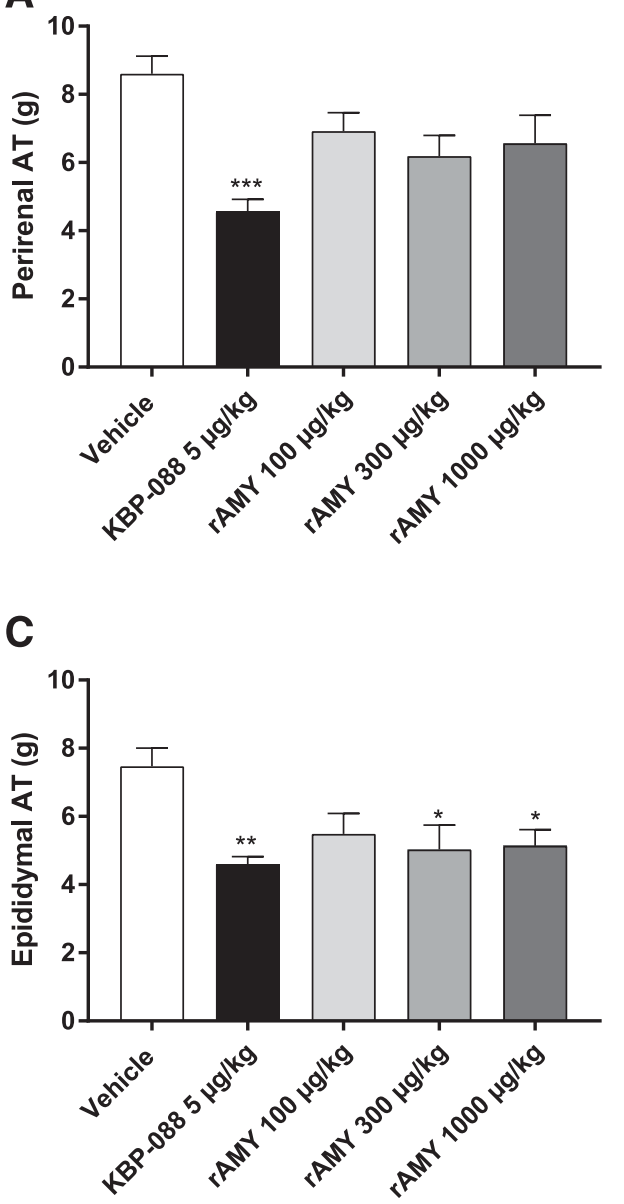

B

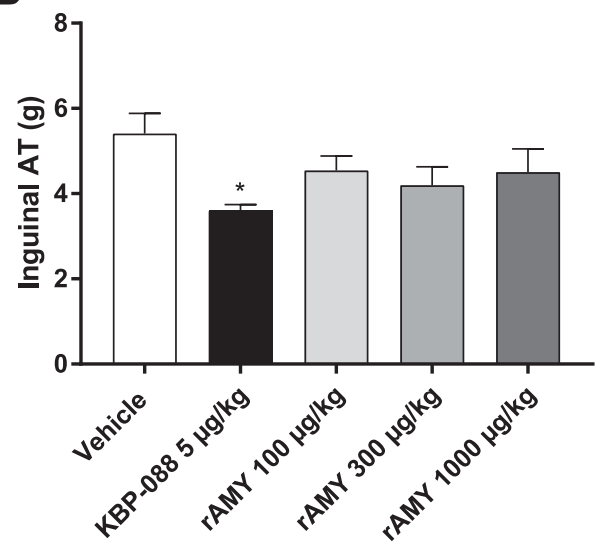

D

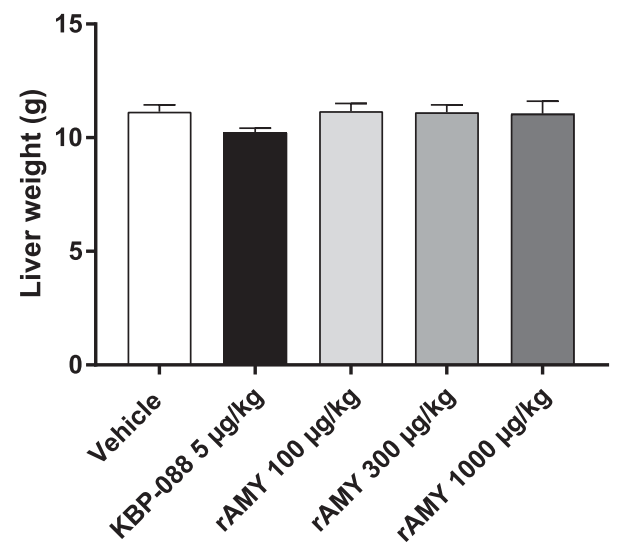

Fig. 3. Weights of perirenal (A), inguinal (B), and epididymal (C) white adipose tissue (AT) and liver (D) from HFD fed Long-Evans rats at study end. $n=8$ rats per group. Statistical analysis between groups was evaluated by one-way ANOVA and Tukey's multiple comparisons test: $* P<0.05, * * P<0.01$, and $* * * P<0.001$ compared with vehicle. All data are mean \pm S.E.M.; rAMY, rat amylin. gastric emptying rate. Here, KBP-088 reduced vehiclecorrected gastric emptying by approximately 55\%, while amylin at 100,300 , and $1000 \mu \mathrm{g} / \mathrm{kg}$ per day reduced vehiclecorrected gastric emptying by $39 \%, 45 \%$, and $38 \%$, respectively (Fig. 5B). Sixty minutes postadministration the treatment effect on gastric emptying was markedly reduced and only KBP-088 tended to differ from vehicle (Fig. 5B). Even though there was no statistical difference between the treatment groups KBP-088 overall tended to delay gastric emptying more than amylin, which was reflected in the lower vehicle-corrected values at all measured timepoints.

Acute Amylin Sensitivity Is Independent of Chronic Treatment. An acute AST was performed after 7, 14, and 21 days of treatment to assess whether the sensitivity to acute amylin dosing was dependent on the chronic treatment and changes during the study (Fig. 6J).

After 7 days of chronic treatment, a single dose of amylin (300 $\mu \mathrm{g} / \mathrm{kg}$ per day) reduced vehicle-corrected food intake 2 hours postinjection in all treatment groups (reduction to $\sim 40 \%$ of vehicle), while no anorectic effect was observed after 4 and 24 hours (Fig. 6, A-C). The group receiving chronic amylin (100 $\mu \mathrm{g} / \mathrm{kg}$ per day) even increased their vehiclecorrected food intake 4 hours postinjection to $\sim 191 \%$ of vehicle (Fig. 6B). During the ASTs at days 14 and 21 the same pattern was observed. However, the group receiving chronic KBP-088 treatment showed a slightly reduced food suppressive effect of amylin compared with day 7 (Fig. 6, D-I). Importantly, there were no significant differences in acute amylin sensitivity between the chronic treatment groups.

\section{Discussion}

In this article, we present data comparing the chronic effect of continuous infusion of the DACRA KBP-088 $(5 \mu \mathrm{g} / \mathrm{kg}$ per day) to increasing doses of rat amylin $(100,300$, or $1000 \mu \mathrm{g} / \mathrm{kg}$ per day) in HFD fed rats. To compare the metabolic effects of the two peptides directly and take the difference in activity into account, peptides were delivered by continuous subcutaneous infusion.

Here, we show that 4 weeks of chronic infusion treatment with KBP-088 and rat amylin induced a marked reduction in body weight gain and food intake in HFD fed rats. The observed effects of amylin on body weight and food intake correlate well with previous studies using amylin infusion in comparable dose ranges (Mack et al., 2003, 2007; Roth et al., 2006). Even though amylin was given in much higher doses than KBP-088, KBP-088 was superior in terms of body weight loss, suppression of food intake, reduction of adipose mass, and improvement of glucose tolerance. Interestingly, the superiority was evident even when correcting for the different activities of the peptides delivered by continuous infusion. Hence, 
A

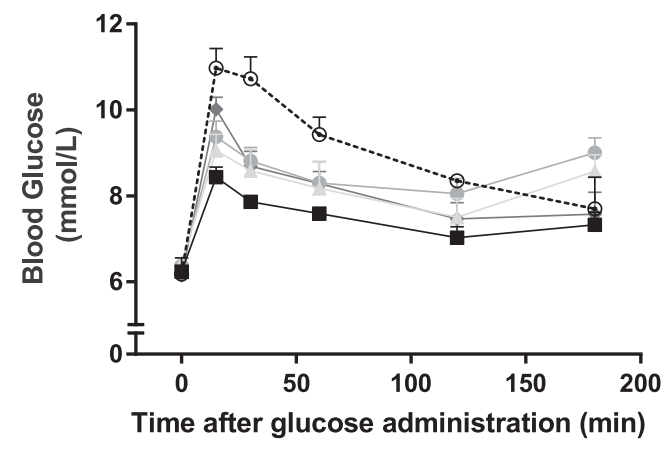

B

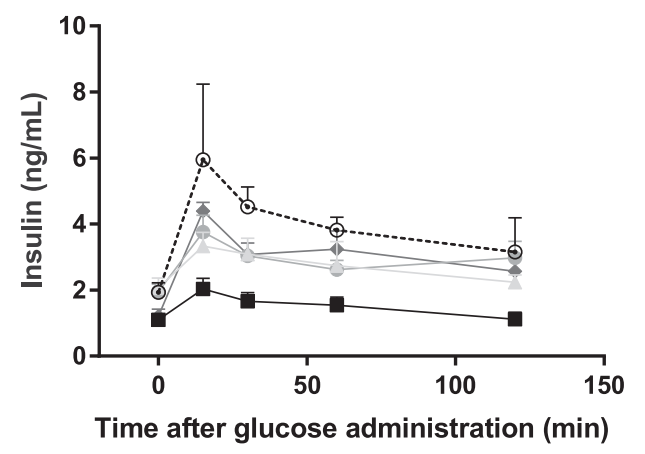

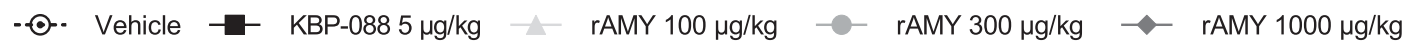
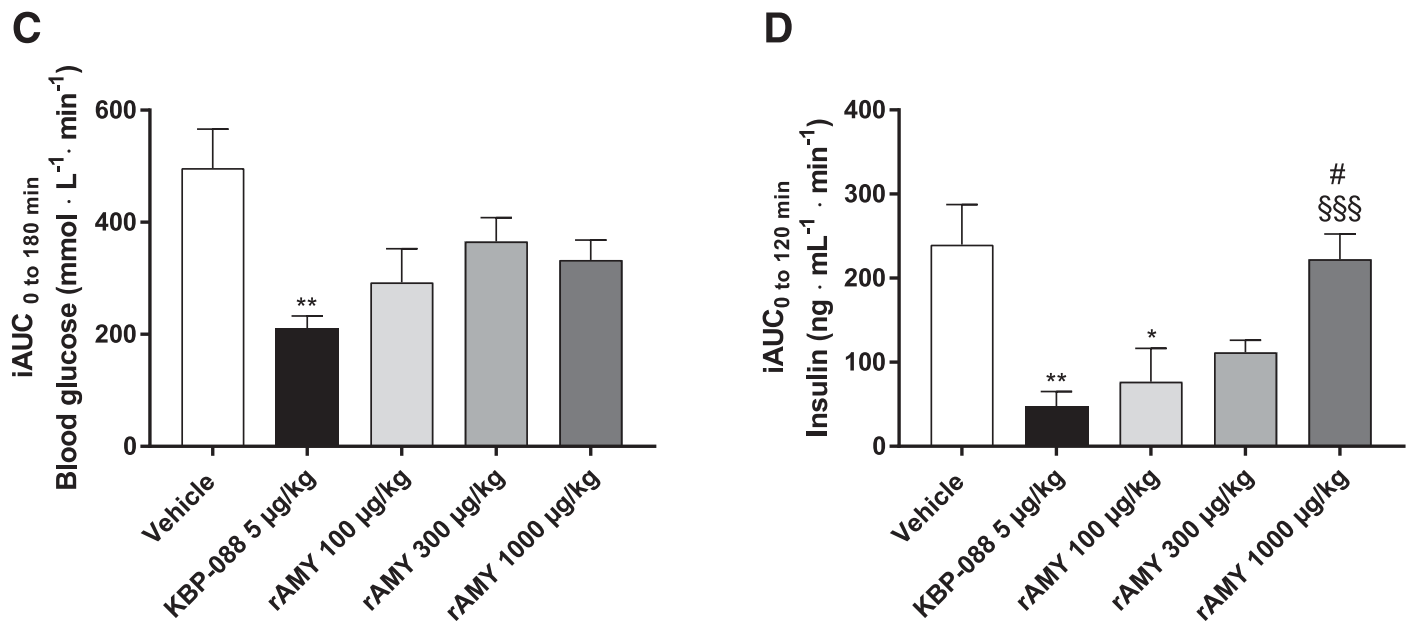

Fig. 4. Plasma glucose (A) and insulin (B) during an OGTT in HFD fed Long-Evans rats treated for 4 weeks. The incremental area under the curve (iAUC) is shown for glucose (C) and insulin (D). $n=8$ rats per group. Statistical analysis between groups was evaluated by one-way ANOVA and Tukey's multiple comparisons test: ${ }^{*} P<0.05$ and ${ }^{* *} P<0.01$ compared with vehicle; ${ }^{\S \S \S} P<0.001$ compared with KBP-088; and ${ }^{\sharp} P<0.05$ compared with amylin $300 \mu \mathrm{g} / \mathrm{kg}$ per day. All data are means \pm S.E.M.; rAMY, rat amylin.

the prolonged receptor activation induced by KBP-088 (Gydesen et al., 2016), as reflected in the acute food intake study, cannot explain the superior effects of KBP-088 in the chronic study, potentially indicating a role for the calcitonin receptor in these additional effects. Interestingly, this corresponds well with a previous study showing that 4-week infusion of the dual agonist davalintide is superior to amylin in inducing body weight loss in obese rats (Mack et al., 2011). Notably, KBP-088 elicits prolonged receptor activation compared with davalintide, and is better in inducing body weight loss when tested head to head with davalintide in vivo (Gydesen et al., 2016).

Interestingly, the intermediate dose of amylin $(300 \mu \mathrm{g} / \mathrm{kg}$ per day) had the greatest efficacy of the tested doses of amylin, with an indication of lower efficacy at the high dose. Another study found the effect of amylin to be dose dependent (Mack et al., 2007), but in this study amylin was not tested in doses above $300 \mu \mathrm{g} / \mathrm{kg}$. Importantly, the stability test of amylin confirmed that the inverse dose response is not due to lost activity of the high-dose peptide (Supplemental Fig. 1).

Previous studies have shown that both amylin infusion (Roth et al., 2006; Trevaskis et al., 2010) and DACRA treatment (Andreassen et al., 2014a; Hjuler et al., 2015, 2016; Gydesen et al., 2016, 2017) reduce plasma insulin in obese rat models, albeit DACRA and amylin have never been compared directly by chronic infusion. The lowest $(100 \mu \mathrm{g} / \mathrm{kg}$ per day) and highest (1000 $\mu \mathrm{g} / \mathrm{kg}$ per day) doses of amylin elicited similar effects on all measured parameters except insulin levels during OGTT. Surprisingly, animals receiving the highest dose of amylin ( $1000 \mu \mathrm{g} / \mathrm{kg}$ per day) did not have reduced plasma insulin levels compared with vehicle. While the basal level of plasma insulin is low in animals receiving the highest dose of amylin, insulin is markedly increased in response to the glucose challenge, resulting in incremental area under the curve values significantly different from the other treatment groups. Obesity-induced hyperamylinemia has been suggested to be an important factor associated with insulin resistance (Beglinger et al., 2014), indicating an association between plasma amylin levels and insulin secretion. We speculate that the highest dose of amylin might result in desensitization of the ability of amylin to reduce insulin secretion, although to fully understand the mechanism further studies are needed. Even though the two lowest doses of amylin (100 and $300 \mu \mathrm{g} / \mathrm{kg}$ per day) significantly reduced insulin levels during an OGTT, the effect on blood 
A

15 minutes

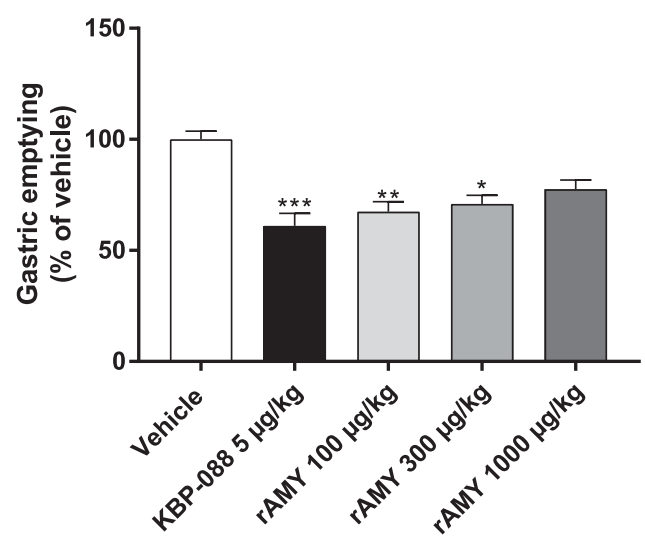

B

30 minutes

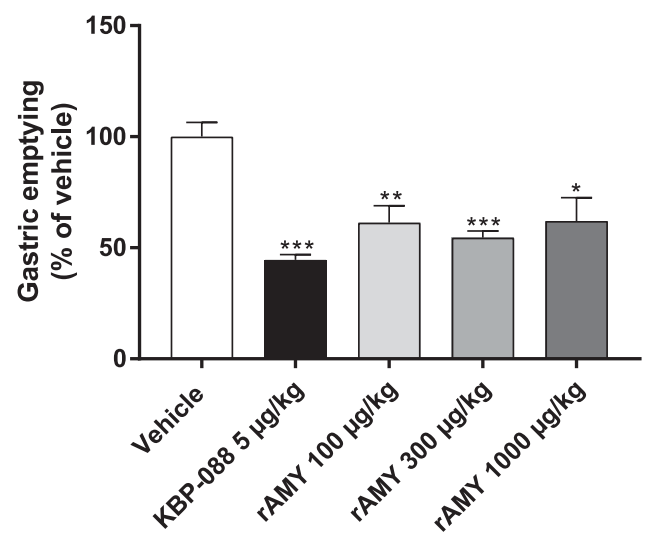

C

60 minutes

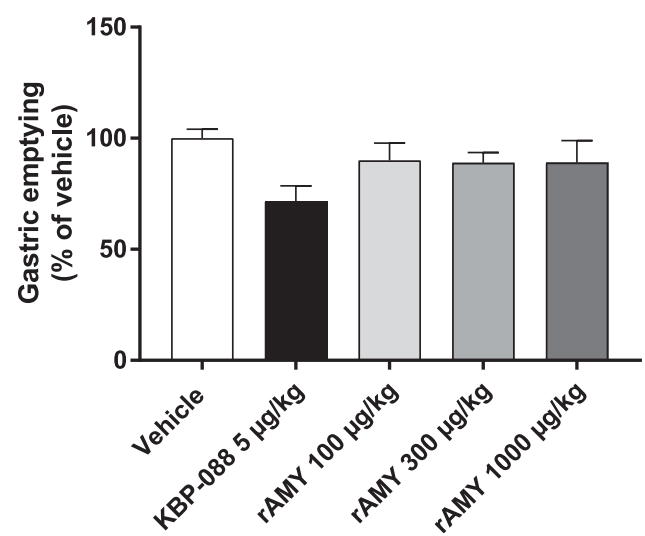

Fig. 5. Gastric emptying in HFD fed Long-Evans rats after 4 weeks of treatment was assessed 15 (A), 30 (B) and 60 (C) minutes post acetaminophen administration. Gastric emptying was estimated by the appearance of acetaminophen in plasma and calculated as percentage of change relative to vehicle. $n=8$ rats per group. Statistical analysis between groups was evaluated by one-way ANOVA and Tukey's multiple comparisons test: $* P<0.05$, $* * P<0.01$, and $* * * P<0.001$ compared with vehicle. All data are means \pm S.E.M.; rAMY, rat amylin.

glucose levels was not as correspondingly low as observed in the KBP-088-treated group, thus again showing a more potent response with KBP-088 independent of the prolonged receptor activation. The superior effects of KBP-088 could likely be related to the ability of KBP-088 to activate both the AMY-R and the CTR (Andreassen et al., 2014b; Gydesen et al., 2016), suggesting that activation of the CTR (which as described previously is an amylin receptor without the RAMP) is important for the efficacy of KBP-088 and other DACRAs. Albeit, to what extent the calcitonin receptor is involved in the beneficial metabolic effects of DACRAs will need further investigations, and additional understanding of the dual or single receptor activation mechanisms is of high pharmaceutical interest. It is unlikely that the superiority of KBP-088 is due to off-target activation of other peptide receptors. First, several studies have shown that DACRAs do not elicit off-target activation of the calcitonin gene-related peptide receptor, which is a closely related member of the same receptor family (Andreassen et al., 2014a; Gydesen et al., 2016, 2017). Second, activation of incretin receptors is unlikely since the glucose-lowering effect of gastric inhibitory polypeptide (Tatarkiewicz et al., 2014; Nørregaard et al., 2018) and glucagon-like peptide-1 receptor agonists (Vilsbøll et al., 2008; Ladenheim, 2015) involves increased postprandial insulin secretion, while KBP-088 reduces plasma insulin levels.

Both amylin and DACRAs are known to delay gastric emptying (Young et al., 1995; Young, 2005; Andreassen et al., 2014a; Hjuler et al., 2016), which can positively affect postprandial blood glucose levels by delaying entry of glucose into circulation. The KBP-088- and amylininduced lowering of gastric emptying rate corresponds well to the effects on blood glucose levels during OGTT, while the significant effects on plasma insulin levels act through a different mechanism independent of gastric emptying.

Similar to other metabolic hormones, such as insulin and leptin, obesity can increase circulating levels of amylininducing hyperamylinemia (Enoki et al., 1992; Pieber et al., 1994), which could potentially affect the response to peripherally administered amylin in HFD fed animals. In addition, data suggest that both diet composition and obesity can affect meal-induced release of amylin (Boyle and Lutz, 2011). The ASTs showed that the acute anorectic effect of amylin injections is independent of both the chronic treatment and the period animals had received treatment, although the suppression of food intake only lasted 2 hours postinjection. Acute dosing of amylin would more closely mimic a physiologic response of meal-induced amylin release, which might explain the consistent anorectic effect of acute amylin dosing observed in the present study. A similar effect was observed in another study showing that hyperamylinemia induced by chronic amylin infusion in lean rats did not alter sensitivity to acute amylin injections (Boyle et al., 2011). Interestingly, the group receiving amylin infusion at the $100 \mu \mathrm{g} / \mathrm{kg}$ per day dose overshot the vehicle food intake $2-4$ hours post acute amylin dosing, indicating that the plasma levels of amylin could somehow affect the acute amylin response. We speculate that this is because the chronic suppression of food intake is less prominent at the $100 \mu \mathrm{g} / \mathrm{kg}$ per day dose than at the other doses; therefore, there is an overshooting effect following the AST. However, this will need further investigation.

In conclusion, KBP-088 is superior to rat amylin in reducing food intake, body weight, and adiposity, and 
A

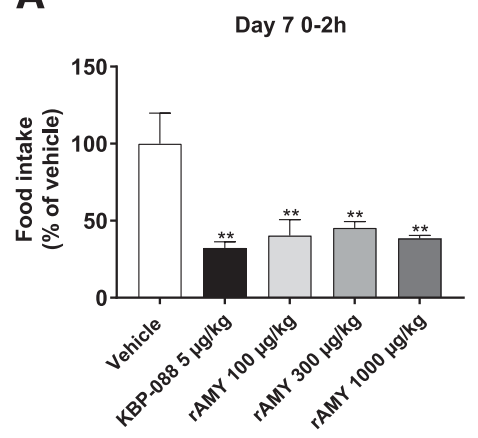

D

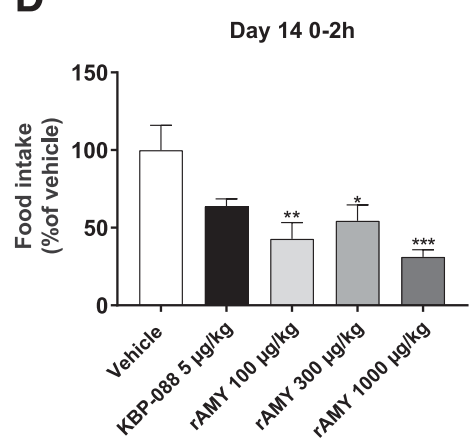

G

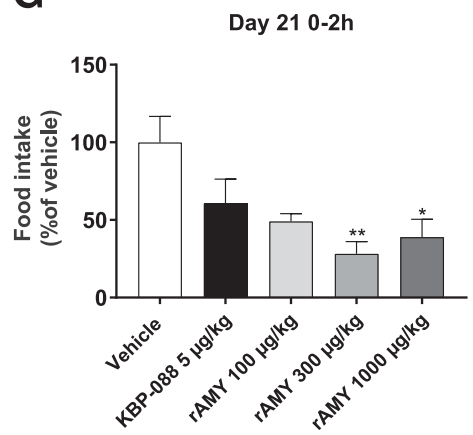

B

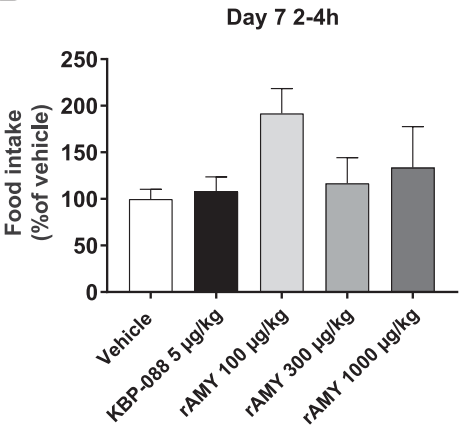

E

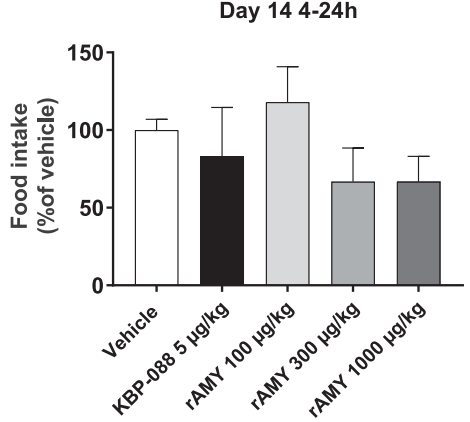

H

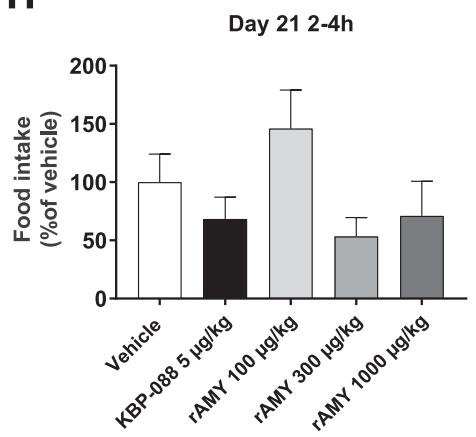

C

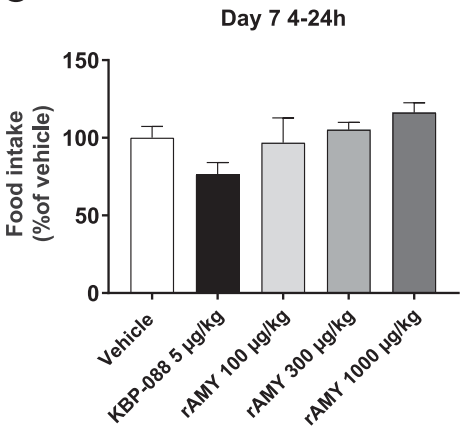

F

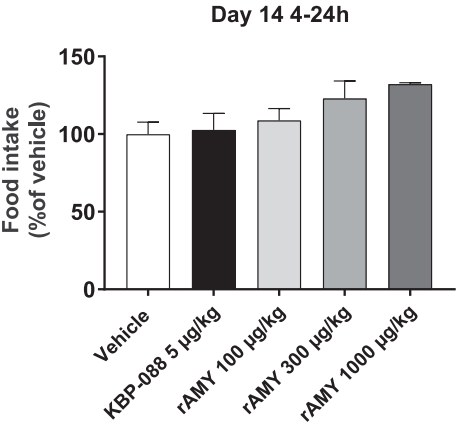

I

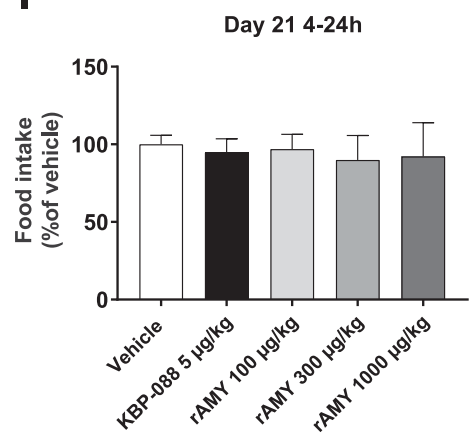

J

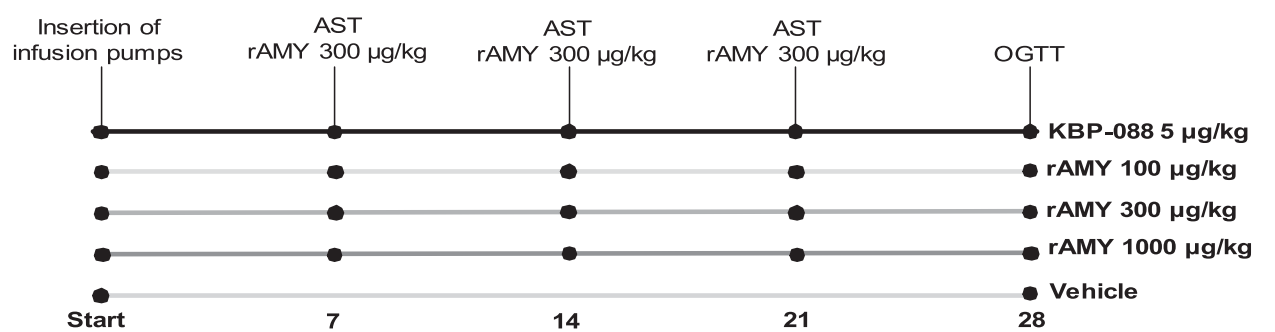

Fig. 6. An acute AST was performed in HFD fed Long-Evans rats after 7 (A-C), 14 (D-F), and 21 (G-I) days of chronic treatment as indicated in the experimental overview $(\mathrm{J})$. All treatment groups received a single subcutaneous dose of amylin $(300 \mu \mathrm{g} / \mathrm{kg})$ at time 0 . Vehicle received a dose of saline. Food intake was monitored following $2(\mathrm{~A}, \mathrm{D}$, and $\mathrm{G}), 4(\mathrm{~B}, \mathrm{E}$, and $\mathrm{H})$, and $24(\mathrm{C}, \mathrm{F}$, and $\mathrm{I})$ hours and are shown as vehicle-corrected values. $n=8$ rats per group. Statistical analysis between groups was evaluated by one-way ANOVA and Dunnett's test for comparison with vehicle: $* P<0.05$, ** $P<0.01$, and $* * * P<0.001$ compared with vehicle. All data are mean \pm S.E.M.; rAMY, rat amylin.

improving oral glucose tolerance, suggesting that the ability of KBP-088 and other DACRAs to effectively activate both the amylin and calcitonin receptors is of importance in terms of efficacy. In addition, the anorectic effect of acute amylin is not compromised by chronic treatment with KBP-088 and amylin.

\section{Authorship Contributions}

Participated in research design: Larsen, Henriksen, Karsdal.

Conducted experiments: Larsen, Gehring.

Performed data analysis: Larsen, Sonne, Andreassen, Gehring.

Wrote or contributed to the writing of the manuscript: Larsen, Henriksen. 


\section{References}

Andreassen KV, Feigh M, Hjuler ST, Gydesen S, Henriksen JE, Beck-Nielsen H, Christiansen C, Karsdal MA, and Henriksen K (2014a) A novel oral dual amylin and calcitonin receptor agonist (KBP-042) exerts antiobesity and antidiabetic effects in rats. Am J Physiol Endocrinol Metab 307:E24-E33.

Andreassen KV, Hjuler ST, Furness SG, Sexton PM, Christopoulos A, Nosjean O, Karsdal MA, and Henriksen K (2014b) Prolonged calcitonin receptor signaling by salmon, but not human calcitonin, reveals ligand bias. PLoS One 9:e92042.

Aronne L, Fujioka K, Aroda V, Chen K, Halseth A, Kesty NC, Burns C, Lush CW, and Weyer C (2007) Progressive reduction in body weight after treatment with the amylin analog pramlintide in obese subjects: a phase 2, randomized, placebocontrolled, dose-escalation study. J Clin Endocrinol Metab 92:2977-2983.

Beglinger S, Meyer-Gerspach AC, Graf S, Zumsteg U, Drewe J, Beglinger C, and Gutzwiller JP (2014) Effect of a test meal on meal responses of satiation hormones and their association to insulin resistance in obese adolescents. Obesity (Silver Spring) 22:2047-2052.

Boyle CN and Lutz TA (2011) Amylinergic control of food intake in lean and obese rodents. Physiol Behav 105:129-137.

Boyle CN, Rossier MM, and Lutz TA (2011) Influence of high-fat feeding, dietinduced obesity, and hyperamylinemia on the sensitivity to acute amylin. Physiol Behav 104:20-28.

Christopoulos G, Perry KJ, Morfis M, Tilakaratne N, Gao Y, Fraser NJ, Main MJ, Foord SM, and Sexton PM (1999) Multiple amylin receptors arise from receptor activity-modifying protein interaction with the calcitonin receptor gene product. Mol Pharmacol 56:235-242.

Enoki S, Mitsukawa T, Takemura J, Nakazato M, Aburaya J, Toshimori H, and Matsukara S (1992) Plasma islet amyloid polypeptide levels in obesity, impaired glucose tolerance and non-insulin-dependent diabetes mellitus. Diabetes Res Clin Pract 15:97-102.

Gydesen S, Andreassen KV, Hjuler ST, Christensen JM, Karsdal MA, and Henriksen K (2016) KBP-088, a novel DACRA with prolonged receptor activation, is superior to davalintide in terms of efficacy on body weight. Am J Physiol Endocrinol Metab 15:E821-E827.

Gydesen S, Andreassen KV, Hjuler ST, Hellgren LI, Karsdal MA, and Henriksen K (2017) Optimization of tolerability and efficacy of the novel dual amylin and calcitonin receptor agonist KBP-089 through dose escalation and combination with a GLP-1 analog. Am J Physiol Endocrinol Metab 313:E598-E607.

Hay DL (2017) Amylin. Headache 57 (Suppl 2):89-96.

Hay DL, Chen S, Lutz TA, Parkes DG, and Roth JD (2015) Amylin: pharmacology, physiology, and clinical potential. Pharmacol Rev 67:564-600.

Hjuler ST, Andreassen KV, Gydesen S, Karsdal MA, and Henriksen K (2015) KBP 042 improves bodyweight and glucose homeostasis with indices of increased insulin sensitivity irrespective of route of administration. Eur J Pharmacol 762:229-238.

Hjuler ST, Gydesen S, Andreassen KV, Karsdal MA, and Henriksen K (2017) The dual amylin- and calcitonin-receptor agonist KBP-042 works as adjunct to metformin on fasting hyperglycemia and $\mathrm{HbA1c}$ in a rat model of type 2 diabetes. $J$ Pharmacol Exp Ther 362:24-30.

Hjuler ST, Gydesen S, Andreassen KV, Pedersen SL, Hellgren LI, Karsdal MA and Henriksen K (2016) The dual amylin- and calcitonin-receptor agonist KBP-042 increases insulin sensitivity and induces weight loss in rats with obesity. Obesity (Silver Spring) 24:1712-1722.

Hollander PA, Levy P, Fineman MS, Maggs DG, Shen LZ, Strobel SA, Weyer C, and Kolterman OG (2003) Pramlintide as an adjunct to insulin therapy improves long-term glycemic and weight control in patients with type 2 diabetes: a 1-year randomized controlled trial. Diabetes Care 26:784-790.

Ladenheim EE (2015) Liraglutide and obesity: a review of the data so far. Drug Des Devel Ther 9:1867-1875.

Mack C, Hoyt J, Moore C, Jodka C, and Sams-Dodd F (2003) Sustained reduction in food intake and body weight in high-fat-fed rats during 28-day amylin infusion. Diabetes 52:A389.
Mack C, Wilson J, Athanacio J, Reynolds J, Laugero K, Guss S, Vu C, Roth J, and Parkes D (2007) Pharmacological actions of the peptide hormone amylin in the long-term regulation of food intake, food preference, and body weight. Am J Physiol Regul Integr Comp Physiol 293:R1855-R1863.

Mack CM, Smith PA, Athanacio JR, Xu K, Wilson JK, Reynolds JM, Jodka CM, Lu MGW, and Parkes DG (2011) Glucoregulatory effects and prolonged duration of action of davalintide: a novel amylinomimetic peptide. Diabetes Obes Metab 13: 1105-1113.

Muff R, Bühlmann N, Fischer JA, and Born W (1999) An amylin receptor is revealed following co-transfection of a calcitonin receptor with receptor activity modifying proteins-1 or -3. Endocrinology 140:2924-2927.

Nørregaard PK, Deryabina MA, Tofteng Shelton P, Fog JU, Daugaard JR, Eriksson PO, Larsen LF, and Jessen L (2018) A novel GIP analogue, ZP4165, enhances glucagon-like peptide-1-induced body weight loss and improves glycaemic control in rodents. Diabetes Obes Metab 20:60-68.

Pieber TR, Roitelman J, Lee Y, Luskey KL, and Stein DT (1994) Direct plasma radioimmunoassay for rat amylin-(1-37): concentrations with acquired and genetic obesity. Am J Physiol 267:E156-E164.

Ratner RE, Dickey R, Fineman M, Maggs DG, Shen L, Strobel SA, Weyer C, and Kolterman OG (2004) Amylin replacement with pramlintide as an adjunct to insulin therapy improves long-term glycaemic and weight control in type 1 diabetes mellitus: a 1-year, randomized controlled trial. Diabet Med 21: 1204-1212.

Riddle M, Frias J, Zhang B, Maier H, Brown C, Lutz K, and Kolterman O (2007) Pramlintide improved glycemic control and reduced weight in patients with type 2 diabetes using basal insulin. Diabetes Care 30:2794-2799.

Roth JD, Hughes H, Kendall E, Baron AD, and Anderson CM (2006) Antiobesity effects of the $\beta$-cell hormone amylin in diet-induced obese rats: effects on food intake, body weight, composition, energy expenditure, and gene expression. Endocrinology 147:5855-5864.

Ryan G, Briscoe TA, and Jobe L (2009) Review of pramlintide as adjunctive therapy in treatment of type 1 and type 2 diabetes. Drug Des Devel Ther 2:203-214.

Smith SR, Aronne LJ, Burns CM, Kesty NC, Halseth AE, and Weyer C (2008) Sustained weight loss following 12-month pramlintide treatment as an adjunct to lifestyle intervention in obesity. Diabetes Care 31:1816-1823.

Tatarkiewicz K, Hargrove DM, Jodka CM, Gedulin BR, Smith PA, Hoyt JA, Lwin A, Collins L, Mamedova L, Levy OE, et al. (2014) A novel long-acting glucosedependent insulinotropic peptide analogue: enhanced efficacy in normal and diabetic rodents. Diabetes Obes Metab 16:75-85.

Trevaskis JL, Turek VF, Wittmer C, Griffin PS, Wilson JK, Reynolds JM, Zhao Y, Mack CM, Parkes DG, and Roth JD (2010) Enhanced amylin-mediated body weight loss in estradiol-deficient diet-induced obese rats. Endocrinology 151: 5657-5668.

Vilsbøll T, Brock B, Perrild H, Levin K, Lervang HH, Kølendorf K, Krarup T, Schmitz O, Zdravkovic M, Le-Thi T, et al. (2008) Liraglutide, a once-daily human GLP-1 analogue, improves pancreatic B-cell function and arginine-stimulated insulin secretion during hyperglycaemia in patients with Type 2 diabetes mellitus. Diabet Med 25:152-156.

Weyer C, Maggs DG, Young AA, and Kolterman OG (2001) Amylin replacement with pramlintide as an adjunct to insulin therapy in type 1 and type 2 diabetes mellitus: a physiological approach toward improved metabolic control. Curr Pharm Des 7 $1353-1373$.

Young A (2005) Inhibition of gastric emptying. Adv Pharmacol 52:99-121.

Young AA, Gedulin B, Vine W, Percy A, and Rink TJ (1995) Gastric emptying is accelerated in diabetic BB rats and is slowed by subcutaneous injections of amylin. Diabetologia 38:642-648.

Address correspondence to: Anna Thors $\emptyset$ Larsen, Nordic Bioscience, Herlev Hovedgade 207, 2730 Herlev, Denmark. E-mail: atl@nordicbio.com 